Proc. Indian Acad. Sci. (Chem. Sci.), Vol. 89, Number 2, April 1980, pp. 87-93. (C) Printed in India.

\title{
Preparation, characterisation and thermal properties of hydrazinium derivatives. Part III
}

\author{
K C PATIL, J P VITTAL and C C PATEL \\ Department of Inorganic and Physical Chemistry, Indian Institute of Science, \\ Bangalore 560 012, India \\ MS received 28 August 1979; revised 31 January 1980
}

\begin{abstract}
Hydrazinium acetate, metavanadate, sulfite, sulphamate and thiocyanate have been prepared by the reaction of corresponding ammonium salts with hydrazine hydrate. The compounds were characterised by chemical analysis and infrared spectra. Thermal behaviour of these hydrazinium derivatives have been investigated using thermogravimetry and differential thermal analysis.
\end{abstract}

Keywords. Hydrazinium salts ; thermal analysis.

\section{Introduction}

Recently we reported the preparation and characterisation of a number of hydrazinium derivatives by the reaction of solid ammonium salts with hydrazine hydrate (Patil et al 1978, 1979a). Differential thermal analysis of a number of hydrazinium derivatives have also been discussed (Patil et al 1979b). In continuation of our studies on hydrazinium salts we have now prepared some more compounds and studied their thermal behaviour using thermogravimetry and differential thermal analysis.

\section{Experimental}

All the ammonium salts used were of analytical grade. Hydrazine hydrate (99$100 \%$ ) was a BDH product. Stoichiometric quantities of an ammonium salt and hydrazine hydrate were mixed when homogeneous solution was obtained with the evolution of ammonia indicating that the reaction was instantaneous. The resulting solution was allowed to crystallise in a vacuum desicator over phosphorous pentoxide. In all the cases the conversion of ammonium salt to hydrazinium salt was quantitative.

The hydrazine content in the hydrazinium salts was estimated volumetrically using potassium iodate solution (0.05 M) under Andrews conditions (Vogel 1951). In hydrazinium thiocyanate and hydrazinium metavanadate it was not possible 
to estimate the hydrazine content by this method since both the thiocyanate and the metavanadate also reacted with potassium iodate. The percentage of thiocyanate in hydrazinium thiocyanate was determined gravimetrically as CuSCN (Vittal et al 1979). The vanadate content in hydrazinium metavanadate was dotermined by thermally decomposing $\mathrm{N}_{2} \mathrm{H}_{6} \mathrm{VO}_{3}$ around $500^{\circ} \mathrm{C}$ and weighing the residue as $\mathrm{V}_{2} \mathrm{O}_{5}$. Infrared spectra of the compounds were recorded using Carl Zoiss UR-10 spectrophotometer as $\mathrm{KBr}$ pollets. The infrared spectrum of hydrazinit $\mathrm{m}$ sulfamate was taken as neat. Differential thermal analysis (DTA) was carried out on an automatic recording DTA-02 Universal Instrument manufactured by FranzWagner Industrielle Elektronik of GDR using about $20 \mathrm{mg}$ of the sample. The heating rate employed was $7^{\circ} \mathrm{C} / \mathrm{min}$. Thermogravimetric (TG) experiments were carried out with Stanton Redcroft TG-750 Thermobalance using 6-8 $\mathrm{mg}$ of the sample with a heating rate of $5^{\circ} \mathrm{C} / \mathrm{min}$. All the DTA and TG experiments were done in air.

\section{Results and discussion}

The reaction of solid ammonium salts with hydrazine hydrate yields the corresponding hydrazinium salts as reported earlier. The reaction is quantitative.

$$
\mathrm{NH}_{4} \mathrm{X}+\mathrm{N}_{2} \mathrm{H}_{4} \mathrm{H}_{2} \mathrm{O} \rightarrow \mathrm{N}_{2} \mathrm{H}_{5} \mathrm{X}(\mathrm{s})+\mathrm{NH}_{3}(\mathrm{~g})+\mathrm{H}_{2} \mathrm{O}(\mathrm{g}) \text {, }
$$

where $\mathrm{X}=\mathrm{CH}_{2} \mathrm{COO}, \mathrm{SCN}, \mathrm{SO}_{8} \mathrm{NH}_{2}$ and $\mathrm{VO}_{3}$,

$$
\left(\mathrm{NH}_{4}\right)_{2} \mathrm{SO}_{3}+2 \mathrm{~N}_{2} \mathrm{H}_{4} \mathrm{H}_{2} \mathrm{O} \rightarrow\left(\mathrm{N}_{2} \mathrm{H}_{5}\right)_{2} \mathrm{SO}_{3}(\mathrm{~s})+2 \mathrm{NH}_{3}(\mathrm{~g})+2 \mathrm{H}_{2} \mathrm{O}(\mathrm{g}) \text {. }
$$

All the hydrazinium salts prepared are hygroscopic white solids, the exceptions being hydrazinium metavanadato which is a brown amorphous solid and hydrazinium sulphamate which is a colourless liquid. The results of chemical analysis, meiting points and IR are given in table 1. All compounds show IR absorption of $v_{N-N}$ characteristic of $\mathrm{N}_{2} \mathrm{H}_{5}+$ around $960-980 \mathrm{~cm}^{-1}$ (Braibanti et al 1968).

\begin{tabular}{|c|c|c|c|c|c|}
\hline \multirow{2}{*}{ Compound } & \multicolumn{2}{|c|}{ Melting point $\left({ }^{\circ} \mathrm{C}\right)$} & \multicolumn{2}{|c|}{$\%$ Hydrazine } & \multirow{2}{*}{$\begin{array}{l}\text { IR absorption } \\
v_{N-N} \mathrm{~cm}^{-1}\end{array}$} \\
\hline & Observed & Reported & Observed & Theoretical & \\
\hline $\begin{array}{l}\text { 1. } \mathrm{N}_{2} \mathrm{H}_{6} \mathrm{COOCH}_{3} \\
\text { 2. } \mathrm{N}_{2} \mathrm{H}_{6} \mathrm{VO}\end{array}$ & $\begin{array}{l}96-98 \\
\text { d }\end{array}$ & $\begin{array}{l}97 \\
. \cdot\end{array}$ & $\begin{array}{r}35 \cdot 49 \\
24 \cdot 23^{*} \\
O_{8}(75 \cdot 05)\end{array}$ & $\begin{array}{l}34 \cdot 78 \\
24 \cdot 24^{*} \\
(74 \cdot 96)\end{array}$ & $\begin{array}{l}980 \\
960\end{array}$ \\
\hline $\begin{array}{l}\text { 3. }\left(\mathrm{N}_{2} \mathrm{H}_{4}\right)_{2} \mathrm{SO}_{2} \\
\text { 4. }\left(\mathrm{N}_{2} \mathrm{H}_{2} \mathrm{SO}_{2} \cdot \mathrm{H}_{2} \mathrm{O}\right. \\
\text { 5. } \mathrm{N}_{2} \mathrm{H}_{3} \mathrm{SCN}\end{array}$ & $\begin{array}{l}71-73 \\
45-46 \\
78-79\end{array}$ & $\begin{array}{l}\ddot{7} \\
7 \overline{7} \cdot 5 \\
\% \text { SC }\end{array}$ & $\begin{array}{c}43.96 \\
38.97 \\
35 \cdot 00^{*} \\
N(63 \cdot 92)\end{array}$ & $\begin{array}{c}43 \cdot 71 \\
39 \cdot 02 \\
35 \cdot 16^{*} \\
(63 \cdot 93)\end{array}$ & $\begin{array}{l}980 \\
980 \\
980\end{array}$ \\
\hline 6. $\mathrm{N}_{8} \mathrm{H}_{8} \mathrm{SO}_{2} \mathrm{NH}_{8}$ & d & .. & $23 \cdot 43$ & $24 \cdot 80$ & 980 \\
\hline
\end{tabular}

Table 1. Analytical data of hydrazinium derivatives.

- Hydrazine content was determined indirectly by estimating the corresponding anion, the percentage of which is given in brackets. 


\subsection{Hydrazinium acetate $\left(\mathrm{N}_{2} \mathrm{H}_{5} \mathrm{COOCH}_{3}\right)$}

TG and DTA curves of $\mathrm{N}_{2} \mathrm{H}_{5} \mathrm{COOCH}_{3}$ are shown in figure 1a. DTA shows two endotherms. The first endothermic peak at $105^{\circ} \mathrm{C}$ is due to the melting of the compound which agrees with the reported value (Hady et al 1969). The second endotherm at $175^{\circ} \mathrm{C}$ is assigned to the decomposition of the melt into gaseous products containing acetic acid and ammonia as found by the qualitative test of the gaseous products. The TG shows a single-step decomposition starting around $75^{\circ} \mathrm{C}$ and ending near $200^{\circ} \mathrm{C}$. The results of TG and DTA are complomentary to each other.

\subsection{Hydrazinium metavanadate $\left(\mathrm{N}_{2} \mathrm{H}_{5} \mathrm{VO}_{3}\right)$}

Our earlier attempts to prepare $\mathrm{N}_{2} \mathrm{H}_{5} \mathrm{CrO}_{4}$ and $\left(\mathrm{N}_{2} \mathrm{H}_{5}\right)_{2} \mathrm{Cr}_{2} \mathrm{O}_{7}$ by the reaction of corresponding ammonium salts with hydrazine hydrate were not successful due to their strong oxidising properties. However, we could obtain hydrazinium metavanadate, $\mathrm{N}_{2} \mathrm{H}_{5} \mathrm{VO}_{3}$ when hydrazine hydrate was added to solid ammonium metavanadate, $\mathrm{NH}_{4} \mathrm{VO}_{3}$ at $0^{\circ} \mathrm{C}$. The analysis of the product showed only $14.20 \%$ $\mathrm{N}_{2} \mathrm{H}_{4}$ against $24 \cdot 28 \% \mathrm{~N}_{2} \mathrm{H}_{4}$ required for the formula. However, the amount $\mathrm{VO}_{3}{ }^{-}$ determined by gravimetric analysis is in good agreement (table 1). The discrepancy in the hydrazine content determined by the volumetric analysis of $\mathrm{N}_{2} \mathrm{H}_{5} \mathrm{YO}_{3}$ has been attributed to the side reaction, where some of the $\mathrm{N}_{2} \mathrm{H}_{5}{ }^{+}$ions are utilised for the reduction of $\mathrm{V}^{v}$ to $\mathrm{V}^{\mathrm{iv}}$. Formation of $\mathrm{N}_{2} \mathrm{H}_{5} \mathrm{VO}_{3}$ was further confirmed by the infrared spectrum of the compound. The characteristic IR absorption of $v_{N-N}$ of $\mathrm{N}_{2} \mathrm{H}_{5}$ is observed at $960^{-1}$. The IR absorption frequencies of $\mathrm{VO}_{3}$ are seen at 870 (vs) and 760 (vs) $\mathrm{cm}^{-1}$.

The reaction of $\mathrm{N}_{2} \mathrm{H}_{5} \mathrm{VO}_{3}$ with concentrated $\mathrm{H}_{2} \mathrm{SO}_{4}$ gave vanadyl sulphate, VOSO ${ }_{4}$ and hydrazine sulphate, $\mathrm{N}_{2} \mathrm{H}_{8} \mathrm{SO}_{4}$. The reaction can be written as:

$$
4 \mathrm{~N}_{2} \mathrm{H}_{5} \mathrm{VO}_{3}+7 \mathrm{H}_{2} \mathrm{SO}_{4} \rightarrow 4 \mathrm{VOSO}_{4}+3 \mathrm{~N}_{2} \mathrm{H}_{6} \mathrm{SO}_{4}+8 \mathrm{H}_{2} \mathrm{O}+\mathrm{N}_{2} \text {. }
$$

Formation of $\mathrm{VOSO}_{4}$ was confirmed by the blue colour of the solution and UV visible spectra. Hydrazine sulfate which precipitates as a white solid was charac-
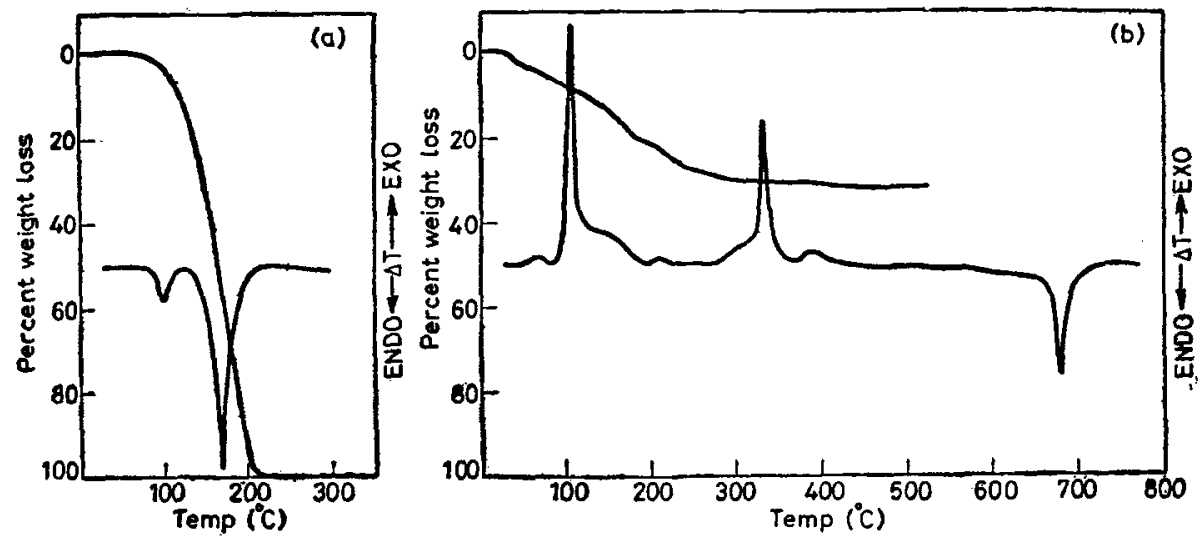

Figure 1. DTA and TG of (a) hydrazinium acetate, $\mathrm{N}_{2} \mathrm{H}_{5} \mathrm{COOCH}_{3}$; (b) hydrazinium metavanadate, $\mathrm{N}_{2} \mathrm{H}_{6} \mathrm{VO}_{3}$. 
terised by its melting point and hydrazine content. Further, the amount of $\mathrm{N}_{2} \mathrm{H}_{6} \mathrm{SO}_{4}$ formed was determined quantitatively by reacting a known amount of $\mathrm{N}_{2} \mathrm{H}_{5} \mathrm{VO}_{3}\left(\mathrm{~g}\right.$ ) with concentrated $\mathrm{H}_{2} \mathrm{SO}_{4}$. In a typical experiment the amount of $\mathrm{N}_{2} \mathrm{H}_{6} \mathrm{SO}_{4}$ formed was $0.60 \mathrm{~g}$. This is rather too low a value compared to the expected value of $0.74 \mathrm{~g}$ for the reaction (3). This discrepancy could be due to the dual nature of the hydrazine which behaves as one-electron and four-electronreductant (Audrieth and Ogg 1951; Krishna Rao and Gopal Rao 1973).

The TG and DTA curves of $\mathrm{N}_{2} \mathrm{H}_{5} \mathrm{VO}_{3}$ are shown in figure $1 \mathrm{~b}$. As can be seen from the TG curve, it is highly unstable and starts decomposing from the room temperature. The DTA shows two exotherms at $104^{\circ} \mathrm{C}$ and $330^{\circ} \mathrm{C}$ followed by an endotherm at $680^{\circ} \mathrm{C}$. The first exotherm at $104^{\circ} \mathrm{C}$ is probably due to the oxidation of hydrazine leaving a black residue which decomposes to vanadium pentoxide. The appearance of $330^{\circ} \mathrm{C}$ exotherm is not clear. However, the residue afier the exotherm $330^{\circ} \mathrm{C}$ was identified as $\mathrm{V}_{2} \mathrm{O}_{5}$ by weight loss in TG as well by the endotherm at $680^{\circ} \mathrm{C}$ in DTA which is due to the melting of $\mathrm{V}_{2} \mathrm{O}_{5}$.

\subsection{Hydrazinium sulphite monohydrate $\left(\mathrm{N}_{2} \mathrm{H}_{5}\right)_{2} \mathrm{SO}_{3} \cdot \mathrm{H}_{2} \mathrm{O}$}

The DTA and TG curves of $\left(\mathrm{N}_{2} \mathrm{H}_{5}\right)_{2} \mathrm{SO}_{3} \cdot \mathrm{H}_{2} \mathrm{O}$ are shown in figure 2a. The DTA shows an endothermic peak at $52^{\circ} \mathrm{C}$ (Melting). The second endotherm near $100^{\circ} \mathrm{C}$ is attributed to the dehydration. The anhydrous salt $\left(\mathrm{N}_{2} \mathrm{H}_{5}\right)_{2} \mathrm{SO}_{3}$ decomposes exothermically at $276^{\circ} \mathrm{C}$. The TG shows a three-step decomposition. The first step is due to dehydration (percentage weight loss; observed 10.00 ; calculated 10.94). The second step is due to the decomposition of the anhydrous salt with a weight loss about $65 \%$. It was not possible to fix the composition of the residue at this stage. The qualitative analysis of the residue obtained by heating $\left(\mathrm{N}_{2} \mathrm{H}_{5}\right)_{2} \mathrm{SO}_{3} \cdot \mathrm{H}_{2} \mathrm{O}$ isothermally at $275^{\circ} \mathrm{C}$ gave tests for $\mathrm{NH}_{4}{ }^{+}, \mathrm{SO}_{4}{ }^{2-}, \mathrm{S}_{2} \mathrm{O}_{3}{ }^{2-}$ and polysulphide. It is possible that $\left(\mathrm{N}_{2} \mathrm{H}_{5}\right)_{2} \mathrm{SO}_{3}$ decomposes exothermically giving sulphur which probably reacts with undecomposed $\mathrm{SO}_{3}{ }^{2-}$ in the melt to give $\mathrm{S}_{2} \mathrm{O}_{3}{ }^{2-}$. The final step (100\% weight loss) has been assigned to the decomposition and volatilisation of the products. There is good agreement in the TG and DTA results.
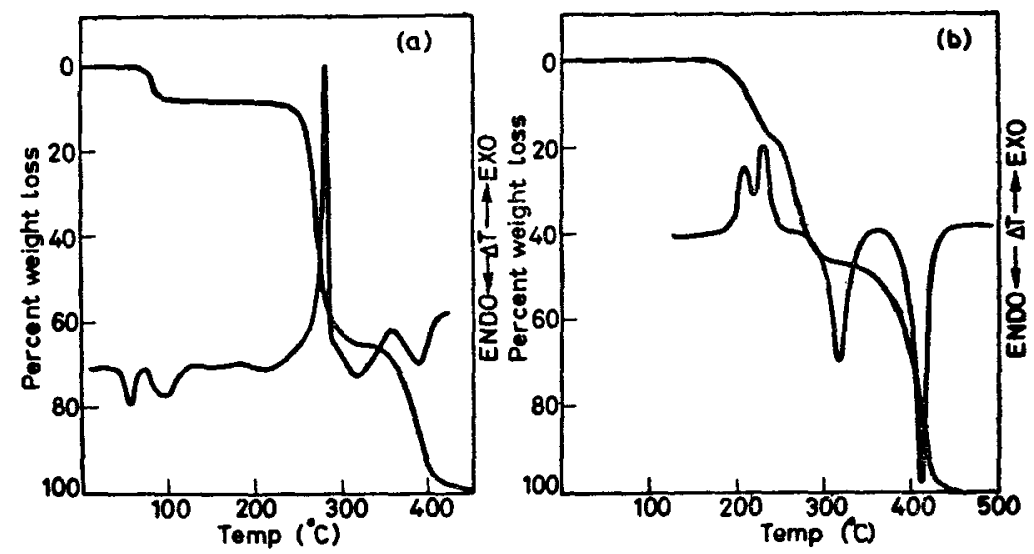

Figure 2. DTA and TG of (a) hydrazinium sulfite monohydrate, $\left(\mathrm{N}_{2} \mathrm{H}_{5}\right)_{2} \mathrm{SO}_{2} \cdot \mathrm{H}_{2} \mathrm{O}$; (b) hydrazinium sulfamate, $\mathrm{N}_{2} \mathrm{H}_{5} \mathrm{SO}_{3} \mathrm{NH}_{2}$. 


\subsection{Hydrazinium sulphamate $\left(\mathrm{N}_{2} \mathrm{H}_{5} \mathrm{SO}_{3} \mathrm{NH}_{2}\right)$}

The TG and DTA curves of $\mathrm{N}_{2} \mathrm{H}_{5} \mathrm{SO}_{3} \mathrm{NH}_{2}$ are shown in figure 2b. The DTA shows two exotherms at 212 and $237^{\circ} \mathrm{C}$ and two endotherms at 317 and $410^{\circ} \mathrm{C}$ respestively. The TG exhibits a two-step decomposition corresponding to the two exotherms and a single-step corresponding to the two endotherms. The liquid $\mathrm{N}_{2} \mathrm{H}_{5} \mathrm{SO}_{3} \mathrm{NH}_{2}$ slowly loses ammonia initially, then decomposes exothermically and vigorously, forming a white solid with the evolution of $\mathrm{NH}_{3}, \mathrm{H}_{2} \mathrm{O}, \mathrm{SO}_{2}$ and $S$, etc., which were detected by qualitative analysis. The TG shows that the compound starts decomposing from $190^{\circ} \mathrm{C}$ with a little break around $215^{\circ} \mathrm{C}$. The white solid formed with about $47 \%$ weight loss was found to be acidic ( $\mathrm{pH} \approx 2$ ), gave effervescence with $\mathrm{NaHCO}_{3}$ solution and showed test for amonium ion.

Hydrazinium sulphamate initially decomposes to give sulphamic acid which appears to decompose instantaneously due to the exothermicity of the first reaction. This acidic residue may be $\mathrm{HN}\left(\mathrm{SO}_{3} \mathrm{NH}_{4}\right)_{2}$ or $\mathrm{NH}_{4} \mathrm{~N}\left(\mathrm{SO}_{3} \mathrm{H}\right)_{2}$ similar to the intermediate formed during the decomposition of ammonium sulphamate or sulphamic acid (Divers and Haga 1896). The acid so formed decomposes to ammonium hydrogen sulphate which decomposes completely (100\% weight loss) in the temperature region 350 to $450^{\circ} \mathrm{C}$ as seen from the TG and DTA with two endotherms.

\subsection{Hydrazinium thiocyanate $\left(\mathrm{N}_{2} \mathrm{H}_{6} \mathrm{SCN}\right)$}

Hydrazinium thiocyanate is known to rearrange into thiosemicarbazide (Raizman and Thompson 1972). This is similar to the classical rearrangement of ammonium cyanate to urea.<smiles>CC(C)(N)NC(=S)NN</smiles>

The conversion of hydrazinium thiocyanate to thiosemicarbazide is about $40 \%$ when the isomerisation is carried out in solution (Sunner 1957). The conversion of $\mathrm{N}_{2} \mathrm{H}_{5} \mathrm{SCN}$ to thiosemicarbazide $(74.8 \%)$ in solid state was observed has been patented recently (Shirai Kozo et al 1976). When $\mathrm{N}_{2} \mathrm{H}_{5} \mathrm{SCN}$ was heated isothermally at $100^{\circ} \mathrm{C}$ for $9 \mathrm{hr}$ at atmospheric pressure, the conversion to thiosemicarbazide was almost $100 \%$. The IR spectrum of the converted sample is st perimposable with that of commercial sample (figure 3).

The DTA and TG curves of $\mathrm{N}_{2} \mathrm{H}_{5} \mathrm{SCN}$ are shown in figure 4. The TG shows no weight loss upto $125^{\circ} \mathrm{C}$. Above this temperature it decomposes with a break at $350^{\circ} \mathrm{C}$ (weight loss about $70 \%$ ). On further heating, the decomposition is about 95\%. The DTA shows the first endotherm at $98^{\circ} \mathrm{C}$ due to melting and partial rearrangement of hydrazinium thiocyanate to thiosemicarbazide since the process is dynamic and not enough time is given for complete conversion. Above this temperature there is an equilibrium between these two compounds. The exothermic peak at $156^{\circ} \mathrm{C}$ is followed by a number of exotherms at $242^{\circ}, 266^{\circ}, 310^{\circ}, 490^{\circ}$, $540^{\circ}, 590^{\circ} \mathrm{C}$, etc., as seen from DTA. The exact nature of these peaks is difficult to assign as TG shows no definite steps corresponding to these temperatures. It is more probable that thiosemicarbazide and hydrazinium thiocyanate react forming a cyclic compound or linear polymeric compound. 


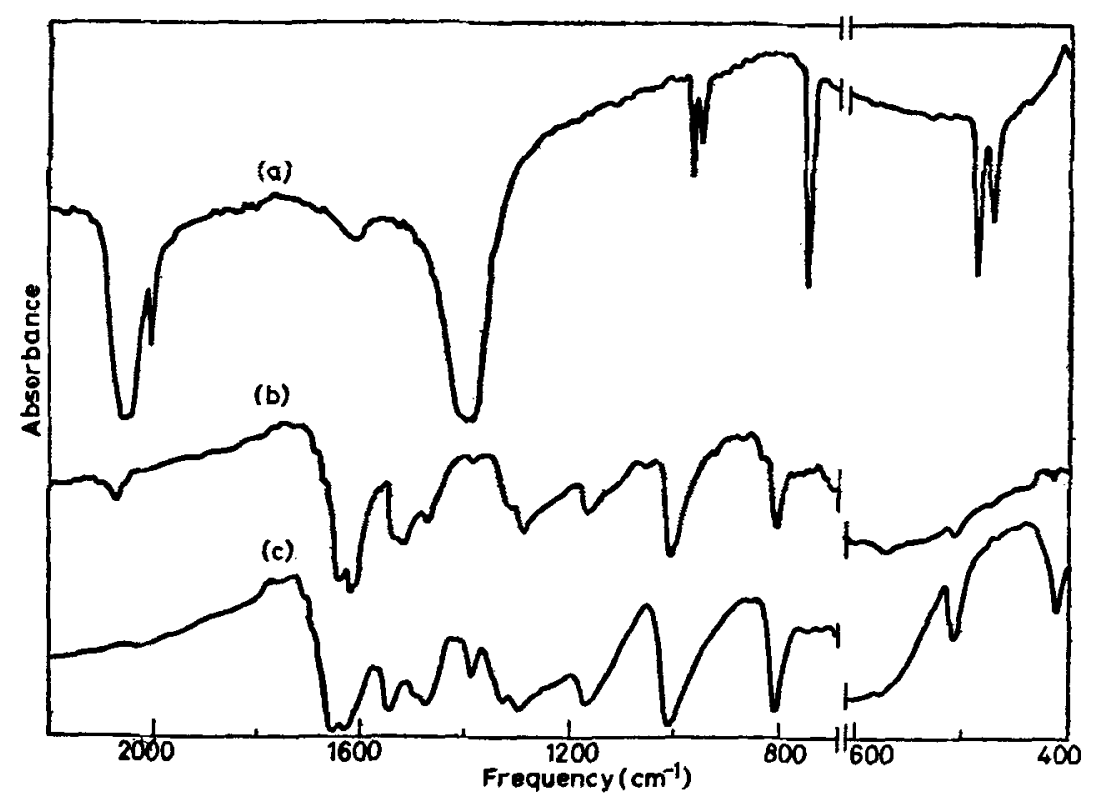

Figure 3. IR absorption spectra of (a) hydrazinium thiocyanate, $\mathrm{N}_{2} \mathrm{H}_{5} \mathrm{SCN}$ ( $\mathrm{KBr}$ pellet); (b) $\mathrm{N}_{2} \mathrm{H}_{5} \mathrm{SCN}$ heated at $100^{\circ} \mathrm{C}$ for $9 \mathrm{hr}$ (KBr pellet); (c) thiosemicarbazide standard sample (Nujol mull).

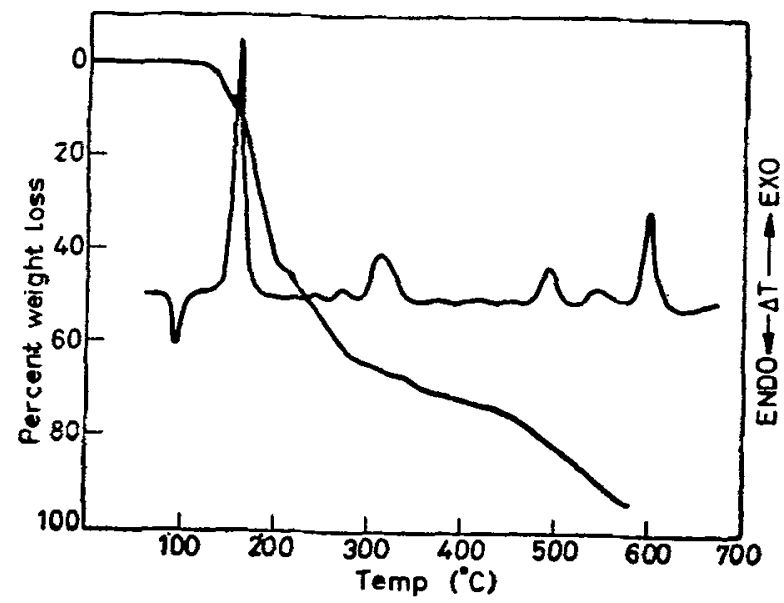

Figure 4. TG and DTA curves of $\mathrm{N}_{2} \mathrm{H}_{5} \mathrm{SCN}$.

\section{Conclusions}

Hydrazinium metavanadate $\mathrm{N}_{2} \mathrm{H}_{6} \mathrm{VO}_{3}$ has been prepared and reported for the first time. The reactions and thermal properties of $\mathrm{N}_{2} \mathrm{H}_{5} \mathrm{VO}_{3}$ have been studied. The eonversion of hydrazinium thiocyanate to thiosemicarbazide is almost quantitative. Thermal properties of hydrazinium acetate, sulphite and sulphamate are also reported for the first time. 


\section{References}

Audrieth L F and Ogg B A 1951 The chemistry of hydrazine (New York: John Wiley) p. 115 Braibanti A I, Dallavalle F, Pellinghelli H A and Leporati E 1968 Inorg. Chem. 71430

Divers, C and Haga T $1896 \mathrm{~J}$. Am. Chem. Soc. 691634

Hady S A, Nahringbaver I and Olovsson I 1969 Acta Chem. Scand. 232764

Krishna Rao P V and Gopal Rao G 1973 Talanta 20907

Krishna Rao P V and Gopal Rao G 1973 Indian J. Chem. 111309

Patil K C, Soundararajan R and Pai Verneker V R 1978 Proc. Indian Acad. Sci. (Chem. Sci.) A87 281

Patil K C, Soundararajan R and Pai Verneker V R 1979a Proc. Indian Acad. Sci. (Chem. Sci.) A88 211

Patil K C, Soundararajan R and Pai Verneker. V R 1979b Thermochim. Acta 31259

Raizman P and Thompson Q E 1972 Chemical analysis, The analytical chemistry of sulphur and its compounds Part II ed.J K Karchmer (New York: Wiley Interscience) Vol. 29 Ch. 10 p. 685

Shirai Kozo, Kobayshi Yukio, Ri Minum 1976 Chem. Abstr. 84 4513b

Sunner S 1957 Acta Chem. Scand. 111766

Vittal J P, Ananthasubramaniam C R, Soundararajan R and Patil K C 1979 Talanta 261041

Vogel A I 1951 A text book of quantitative inorganic analysis (London: Longmans Green) p. 365 